\title{
PENGARUH SERVICE QUALITY DAN STAFF BEHAVIOUR TERHADAP BRAND LOYALTY TIKI DI JAKARTA UTARA: CUSTOMER SATISFACTION SEBAGAI VARIABEL MEDIASI
}

\author{
Rendy Surya \\ Program Studi Magister Manajemen Universitas Tarumanagara \\ rndy11493@hotmail.com
}

Masuk : 05-12-2017, revisi : 20-12-2017 diterima untuk diterbitkan : 20-12-2017

\begin{abstract}
The purposes of this study are: First, to explore the effect among service quality on brand loyalty. Second, to explore the effect among staff behaviour on brand loyalty. Third, to explore the effect among service quality on customer satisfaction. Fourth, to explore the effect of customer satisfaction on brand loyalty. Fifth, to find out if customer satisfaction is able to mediate service quality toward brand loyalty. The populations of this research are all TIKI's customer in Jakarta. The samples of this research are collected from TIKI's customer in North Jakarta. The method of data collection was conducted by distributing questionnaires 200 respondents. The technique of data analysis used in this study was Partial Least Square and indirect effect test for mediation variable to example the hypotheses. The result are: first, the relationship between service quality have a significant and positive effect toward brand loyalty; second, the relationship between staff behaviour have a significant and positive effect toward brand loyalty; third, the relationship between service quality have a significant and positive effect toward customer satisfaction; forth, customer satisfaction have a significant and positive effect toward brand loyalty; fifth, customer satisfaction will mediate the effect between service quality on brand loyalty.
\end{abstract}

Keywords: Service Quality, Staff Behaviour, Customer Satisfaction, Brand Loyalty

\section{PENDAHULUAN}

\section{Latar Belakang Masalah}

Ekonomi Indonesia ternyata tidak seindah yang digembor-gemborkan oleh pemerintah. Boleh saja secara akumulasi pertumbuhan ekonomi Indonesia mencapai kembali ke level 5\%, tetapi berbagai sektor mengalami penurunan yang juga tidak sedikit. Bahkan patut untuk dikhawatirkan. Asumsi awal dari berbagai kalangan pengamat, bahwa terjadinya penurunan daya beli masyarakat selama proses pemulihan ekonomi. Di sisi lain juga ada transformasi bisnis ke dunia online yang lebih efisien bagi konsumen maupun pedagang (Jefriando, 2017).

Industri ritel tanah air tengah menghadapai persoalan pelik. Satu per satu pelaku industri ritel di Indonesia mulai mengehentikan operasional gerai ritelnya. Tercatat, hingga saat ini sudah ada beberapa pelaku usaha ritel yang menutup gerai usahanya, mulai dari 7-Eleven, PT Matahari Department Store (Julianto, 2017).

Menyikapi adanya fenomena yang sedang terjadi pada sektor retail tersebut yaitu banyak retail yang menutup gerainya, retail di Indonesia khusunya di Jakarta. Tiki adalah salah satu industri retail yang cukup besar dan telah menjamur di Indonesia, oleh karena itulah peneliti tertarik untuk meneliti pengaruh Service Quality dan Staff Behaviour terhadap Brand Loyalty TIKI di Jakarta Utara dengan Customer Satisfaction sebagai variabel mediasi.

\section{Pembatasan Masalah}

Berdasarkan pada identifikasi masalah terdapat banyak faktor-faktor yang dapat mempengaruhi brand loyalty. Agar lebih efektif dan efisien baik dari waktu, tenaga maupun biaya penelitian ini dibatasi hanya pada service quality dan staff behaviour terhadap brand loyalty dengan customer satisfaction sebagai variabel mediasi. 


\section{Tujuan Penelitian}

a. Untuk mengetahui pengaruh service quality terhadap brand loyalty pada pelanggan TIKI di Jakarta Utara.

b. Untuk mengetahui pengaruh staff behaviour terhadap brand loyalty pada pelanggan TIKI di Jakarta Utara.

c. Untuk mengetahui pengaruh service quality terhadap customer satisfaction pada pelanggan TIKI di Jakarta Utara.

d. Untuk mengetahui pengaruh customer satisfaction terhadap brand loyalty pada pelanggan TIKI di Jakarta Utara.

e. Untuk mengetahui apakah customer satisfaction dapat memediasi pengaruh service quality terhadap brand loyalty pada pelanggan TIKI di Jakarta Utara.

\section{TINJAUAN PUSTAKA}

Kesetiaan merek merupakan suatu kondisi di mana konsumen memiliki sikap yang positif terhadap merek tersebut dan memiliki komitmen untuk melakukan pembeliannya di masa mendatang. Schiffman \& Kanuk (2010:88) menyatakan brand loyalty sebagai berikut: "customers' consistent preference and/or purchase of the same brand in a specific product or service category." Menurut Lau \& Lee (1999) kesetiaan terhadap merek merupakan perilaku niat untuk membeli sebuah produk dan mendorong orang lain untuk melakukan hal yang sama sehingga memberikan keuntungan bagi perusahaan. Menurut Nam, Ekinci \& Whyatt (2011:1015) menyatakan "brand loyalty as the consumer's intention to visit or willingness to recommend the brand." Kepuasan pelanggan merupakan hasil persepsi individu dari kinerja produk atau jasa yang dirasakan terhadap harapan yang didapat dari produk dan jasa tersebut (Schiffman \& Kanuk, 2010). Menurut Kotler \& Keller (2012:150) menyatakan "satisfaction is a person's feeling of pleasure or disappointment that result from comparing a product's perceived performance (or outcome) to expectations."

Menurut Zeithaml (1988) menjelaskan bahwa service quality sebagai berikut: "the consumer's judgement about the overall excellence or superiority of a service." Parasuraman, Zeithaml \& Berry (1985:42) "service quality is the result of a comparison between what consumers consider the service should be and their perceptions about the performance offered by the service provider." Menurut Palmer (2011:287) menyatakan "service quality is a highly abstract construct, in contrast to goods where technical aspects of quality predominate." Nam, Ekinci \& Whyatt menyatakan "staff behaviour is the image projected by competence, helpfulness, friendliness and responsiveness of the employees." Menurut Madanoglu (2004) staff behaviour adalah sebuah sikap pelayanan individual yang baik kepada pelanggan merupakan salah satu kunci yang berperan penting dalam mencapai keunggulan kompetitif suatu perusahaan yang dapat mempengaruhi tingkat kepuasan dari pelanggan. Teori ini menunjukkan bahwa agar pelanggan menjadi loyal terhadap suatu merk maka perlu diperhatikan beberapa hal diatas seperti kepuasan pelanggan, kualitas pelayanan dan sikap pelayanan.

\section{Hipotesis}

Hipotesis 1 : terdapat pengaruh positif antara service quality terhadap brand loyalty pada pelanggan TIKI di Jakarta Utara.

Hipotesis 2 : terdapat pengaruh positif antara staff behaviour terhadap brand loyalty pada pelanggan TIKI di Jakarta Utara.

Hipotesis 3 : terdapat pengaruh positif antara service quality terhadap customer satisfaction pada pelanggan TIKI di Jakarta Utara.

Hipotesis 4 : terdapat pengaruh positif antara customer satisfaction terhadap brand loyalty pada pelanggan TIKI di Jakarta Utara.

Hipotesis 5 : customer satisfaction memediasi pengaruh service quality secara positif terhadap brand loyalty pada pelanggan TIKI di Jakarta Utara. 


\section{METODOLOGI PENELITIAN}

Populasi dari penelitian ini adalah pelanggan TIKI di Jakarta. Kemudian, metode pemilihan sampel yang digunakan adalah metode non-probability sampling dan teknik pengambilannya menggunakan purposive sampling. Sampel diambil dari pelanggan yang sudah pernah menggunakan jasa TIKI di Jakarta Utara. Ukuran sampel yang digunakan dalam penelitian ini adalah sebanyak 200 orang. Jumlah ini mengacu pada pendapat Wijaya (2009) bahwa pengambilan sampel yang efektif berkisar 150-500 sampel. Metode pengumpulan datanya dengan menyebarkan kuesioner. Jenis kuesioner yang digunakan menggunakan sistem skala likert.

\section{Deskripsi Subjek Penelitian}

Terdapat 200 responden yang berpartisipasi dalam penelitian ini yang terdiri dari wanita (119 orang) dan pria (81 orang). Responden kebanyakan berada pada berusia antara 21-30 tahun (107 orang), dengan pendidikan akhir SMA (118 orang), sebagai pelajara/mahasiswa (122 orang) dengan pengeluaran perbulannya pengeluaran antara tiga juta rupiah hingga empat juta rupiah per bulan (98 orang).

\section{Analisis Partial Least Square (PLS)}

Partial Least Square (PLS) merupakan metode umum untuk mengestimasi path model yang menggunakan konstruk laten dengan multiple indikator. Analisis data dapat dilakukan dengan menggunakan software Partial Least Square, SmartPLS. Dengan merancang inner model dan outer model (Kevin \& Halim, 2017). Merancang inner model untuk mengetahui nilai AVE, composite realibility, dan cronbach's alpha. Berdasarkan hasil uji validitas diketahui seluruh item pertanyaan adalah valid. Karena didapatkan bahwa nilai AVE > 0,5.

Tabel 1

Hasil Uji Validitas

\begin{tabular}{lc}
\hline \multicolumn{1}{c}{ Variabel } & Average Variance Extracted (AVE) \\
\hline Staff Behaviour & 0.677 \\
Service Quality & 0.712 \\
Customer Satisfaction & 0.748 \\
Brand Loyalty & 0.738 \\
\hline
\end{tabular}

Kemudian, berdasarkan hasil uji reliabilitas diketahui bahwa alat ukur realibel. Karena didapatkan bahwa nilai composite realibility > 0,7 dan nilai cronbach's alpha > 0,6.

\section{Tabel 2}

\section{Hasil Uji Reliabilitas}

\begin{tabular}{lcc}
\hline \multicolumn{1}{c}{ Variabel } & Cronbach's Alpha & Composite Reliability \\
\hline Staff Behaviour & 0.838 & 0.893 \\
Service Quality & 0.970 & 0.974 \\
Customer Satisfaction & 0.915 & 0.937 \\
Brand Loyalty & 0.910 & 0.933 \\
\hline
\end{tabular}

Merancang outer model agar dapat menganalisis path coefficient yang nantinya digunakan untuk menguji hipotesis. Kemudian, untuk mengetahui efek dari variabel memediasi, maka dilakukan uji indirect effect dengan ketentuan nilai signifikan $p$-value $<0,05$. Diketahui hasil dari penelitian menunjukkan bahwa variabel mediasi memediasi secara positif dan signifikan.

Tabel 3

\section{Hasil Uji Indirect Effect}

\section{Operasionalisasi Variabel}

$\begin{array}{lccc}\text { Variabel } & \text { Standard Deviation } & \text { t Statistics } & \text { P Values } \\ \text { SQ } \rightarrow \text { BL } & 0.055 & 9.869 & 0.000\end{array}$

Service quality merupakan penilaian konsumen atau pelanggan terhadap semua layanan yang diterima, semakin baik layanan makan semakin baik pula penilaiannya. Indikator dari service quality adalah tangibles, reliability, responsiveness, assurance, dan empathy.

Staff behaviour merupakan kesan yang diperhitungkan melalui kompetensi, sikap menolong, keramahan dan tanggung jawab dari pelayan.

Customer satisfaction merupakan perasaan yang dihasilkan oleh konsumen atas penilaian dari kinerja produk atau jasa berdasarkan dari segi fitur, layanan serta pemenuhan proses 
pelayanan yang diperoleh. Indikator dari customer satisfaction adalah did the right thing, wise choise, satisfied with the decision, satisfying consumers need dan happy.

Brand loyalty merupakan konsistensi dari pelanggan dalam pembelian merek yang sama dalam kategori produk atau layanan tertentu. Indikator dari brand loyalty adalah recommend, say positive things, first choice, encourage dan do more business.

Hasil Pengujian

Tabel 4

Hasil Uji Hipotesis

\begin{tabular}{ccccc}
\hline Model & Variabel & Standard Deviation & T Statistics & P Values \\
\hline 1 & SQ -> BL & 0.073 & 2.225 & 0.027 \\
2 & SB -> BL & 0.066 & 2.330 & 0.020 \\
3 & SQ -> CS & 0.039 & 18.471 & 0.000 \\
4 & CS -> BL & 0.078 & 6.728 & 0.000 \\
\hline
\end{tabular}

Uji Hipotesis 1 terdapat pengaruh positif antara service quality terhadap brand loyalty

Hasil dari penelitian ini menujukan bahwa service quality mempengaruhi variabel brand loyalty secara positif dengan tingkat signifikansi 0,027 lebih kecil dari $\alpha=0,05$. Jadi dapat disimpulkan $\mathrm{H}_{1}$ tidak ditolak.

Uji Hipotesis 2 terdapat pengaruh positif antara staff behaviour terhadap brand loyalty

Hasil pada penelitian ini menunjukkan bahwa staff behavior mempengaruhi variabel brand loyalty secara positif dengan tingkat signifikansi 0,020 lebih kecil dari $\alpha=0,05$. Jadi dapat disimpulkan $\mathrm{H}_{2}$ tidak ditolak.

Uji Hipotesis 3 terdapat pengaruh positif antara service quality terhadap customer satisfaction

Hasil pada penelitian ini menunjukkan bahwa service quality mempengaruhi variabel customer satisfaction secara positif dengan tingkat signifikansi 0,000 lebih kecil dari $\alpha=0,05$. Jadi dapat disimpulkan $\mathrm{H}_{3}$ tidak ditolak.

Uji Hipotesis 4 terdapat pengaruh positif antara customer satisfaction terhadap brand loyalty

Hasil pada penelitian ini menunjukkan bahwa customer satisfaction mempengaruhi variabel brand loyalty secara positif dengan tingkat signifikansi 0,000 lebih kecil dari $\alpha=0,05$. Jadi dapat disimpulkan $\mathrm{H}_{4}$ tidak ditolak.

Uji Hipotesis 5 customer satisfaction memediasi pengaruh service quality secara positif terhadap brand loyalty

Hasil pada penelitian ini menunjukkan bahwa customer satisfaction memediasi pengaruh service quality secara positif terhadap brand loyalty pada pelanggan TIKI di Jakarta Utara dengan signifkansi sebesar 0,000 atau kurang dari 0,05. Jadi dapat disimpulkan bahwa $\mathrm{H}_{5}$ tidak ditolak.

\section{Pembahasan}

Hasil analisis data validitas dan reliabilitas menunjukkan bahwa semua variabel valid dan reliabel. Valid karena nilai Loading Factor untuk semua butir pernyataan pada setiap atribut sudah memenuhi syarat dan nilai Average Variance Extracted juga sudah memenuhi syarat. Kemudian, dikatakan reliabel karena nilai koefisien Cronbach Alpha dan nilai Composite Reliability sudah memenuhi syarat ketentuan oleh karena itu dapat dikatakan bahwa konstrak memiliki reliabilitas yang tinggi atau reliable. Hal ini menunjukkan bahwa kuesioner sebagai alat ukur tersebut layak untuk dilanjutkan ke analisis selanjutnya.

Dari hasil penelitian ini, perlu diperhatikan agar perusahaan TIKI meningkatkan kualitas pelayan yang nantinya akan menyebabkan konsumen melakukan pemakaian ulang jasa kurir merek TIKI itu sendiri, sehingga dapat meningkatkan pendapatan perusahaan. Pelanggan memiliki rasa loyalitas yang tinggi terhadap merek TIKI dikarenakan sikap dari karyawan yang baik yang dirasakan konsumen sehingga dapat meningkatkan loyalitas terhadap suatu merek. Jadi perlu diperhatikan oleh perusahaan TIKI agar meningkatkan sikap dari para karyawannya, mungkin dengan mengadakan pelatihan untuk para karyawan ataupun penyuluhan tentang cara melayani konsumen dengan baik sehingga terbentuknya loyalitas terhadap merek TIKI. 
Pelanggan akan merasa puas apabila menerima pelayanan yang baik, dalam artian bahwa kualitas pelayanan dari TIKI itu bagus sehingga para pelanggan akan merasa puas telah memakai jasa TIKI. Jadi perlu diperhatikan oleh perusahaan TIKI agar terus meningkatkan kualitas pelayanan sehingga para pelanggan akan merasa puas telah memakai jasa kurir TIKI. Para pelanggan merasa puas akan pelayanan yang diberikan oleh TIKI yang mendorong terbentuknya loyalitas untuk memakai jasa TIKI. Jadi, semakin tinggi tingkat kepuasan yang diberikan oleh TIKI, maka semakin tinggi pula tingkat loyalitas terhadap TIKI. Kemudian, dengan ditingkatkannya kualitas pelayanan di gerai-gerai TIKI, maka secara tidak langsung pelanggan akan merasakan bahwa pelayanan TIKI lebih baik dibandingkan jasa antar barang dan dokumen lainnya, sehingga mendorong terbentuknya kepuasan yang dapat meningkatkan loyalitas terhadap merek TIKI.

\section{KESIMPULAN}

a. Terdapat pengaruh yang positif antara service quality terhadap brand loyalty pada pelanggan TIKI di Jakarta Utara.

b. Terdapat pengaruh yang positif antara staff behaviour terhadap brand loyalty pada pelanggan TIKI di Jakarta Utara.

c. Terdapat pengaruh yang positif antara service quality terhadap customer satisfaction pada pelanggan TIKI di Jakarta Utara.

d. Terdapat pengaruh yang positif customer satisfaction terhadap brand loyalty pada pelanggan TIKI di Jakarta Utara.

e. Customer satisfaction memediasi pengaruh service quality secara positif terhadap brand loyalty pada TIKI di Jakarta Utara.

\section{DAFTAR PUSTAKA}

Jefriando, M. (2017). Potret Nyata Lesunya Ekonomi Indonesia. Detik Finance, 2017. 28 Oktober 2017. http://finance.detik.com/berita-ekonomi-bisnis/3575532/potret-nyatalesunya-ekonomi-indonesia.

Julianto, P. (2017). Ritel Banyak Yang Tutup, apa yang sebenarnya terjadi. Kompas 2017. 28 Oktober 2017.

Kevin \& Susanto, H. The influence of financial knowledge, financial confidence, and income on financial behaviour amon the workforce in jakarta. Jurnal Mix, 7(1).

Kotler, P., \& Keller, K. L. (2012). Marketing Management, (14 ${ }^{\text {th }}$ ed.), New Jersey: Pearson Education.

Lau, G. T., \& Lee, S. H. (1999). Consumer' trust in a brand and the link to brand loyalty. Journal of Market Focused Management, 4, 341-370.

Madanoglu, M. (2004). Validating restaurant service quality dimensions. Journal of Foodservice Business Research, 7(4), 127-147.

Nam, J., Ekinci, Y., \& Whyatt, G. (2011). Brand equity, brand loyalty and consumer satisfaction. Annals of Tourism Research, 38(3), 1009-1030.

Nam, J., Zeithaml, V. A., \& Berry, L. L. (1988). SERVQUAL: A Multiple-item Scale for Measuring Consumer Perceptions of Service Quality. Journal of Retailling, 70(3), 201230.

Palmer, A. (2011). Principles of Service Marketing, (6 ${ }^{\text {th }}$ ed.), New York: McGraw-Hill.

Schiffman, L. G., \& Kanuk, L. L. (2010). Consumer Behavior, (10 ${ }^{\text {th }}$ ed.), New Jersey: Pearson Education.

Wijaya, T. (2009). Analisis Structural Equation Modeling Menggunakan AMOS untuk Penelitian. Yogyakarta: Universitas Atma Jaya Yogyakarta.

Zeithaml, V. A. (1988). Consumer perception of price, quality, and value: A means-end model and synthesis of evidence. Journal of Marketing, 52, 2-22. 